\title{
THE USER OF ADSORPTION FOR PURIFICATION OF WASTEWATER FROM THE PRODUCTION OF PHENOL-FORMALDEHYDE RESINS
}

\author{
Irina V. Timoshchuk
}

Kemerovo Institute of Food Science and Technology (University), Stroiteley blvd. 47, Kemerovo, 650056 Russian Federation

Received March 28, 2016;

*e-mail: ecolog1528@yandex.ru

Accepted in revised form May 18, 2016;

Published June 30, 2016

\begin{abstract}
To increase ecological safety of phenol-formaldehyde resins production of the novolac type, the adsorption technology for purification of wastewater containing mainly phenol and formaldehyde was developed. The research of organic substances adsorption (formaldehyde, phenol) from individual aqueous solutions and their mixtures on carbon sorbents grades AG-3, AG-OV-1, SKD-515, BAU, ABG, XAU was conducted, this grades differ in composition, method of producing, structure, and chemical state of the surface. The basic laws, characteristics and mechanism of adsorption of organic substances on activated carbon (AU) were established. The mechanism of mass transfer during adsorption of a mixture of phenol and formaldehyde on the investigated sorbents was showed, and the external mass transfer coefficients were calculated. There was proposed the method of optimization of parameters and continuous adsorption treatment process modes, based on the fundamental external diffusion dynamics adsorption formula using the adsorption constants of the Dubinin-Radushkevich's equation and kinetic dependencies. The main features of the adsorption dynamics were established, which allowed to determine the duration of column operation, the amount of feed water depending on the throughput rate, the height of the fixed bed and size of the column. According to the results of experimental studies and derivatographic analysis we developed the technology of carbon sorbents regeneration after adsorption of formaldehyde and phenol mixture, which allowed to restore the AC (activated carbon) sorption capacity to $95-98 \%$. On the basis of aggregate balance studies, kinetics and dynamics of adsorption process, optimization of the cleaning regime and the parameters of adsorption column using mathematical modeling, we recommend the technological solution for waste water purification from phenol and formaldehyde, which are formed in the process of phenol-formaldehyde resins of the novolac type production.
\end{abstract}

Keywords: adsorption, activated carbon, waste water, phenol, formaldehyde

\section{INTRODUCTION}

The protection of environment is currently one of the most important factors influencing the further development of mankind. Over the last years, the problems connected with the pollution of the hydrosphere intensified. The discharge of insufficiently purified waste water in water bodies leads to decrease in biological productivity of ecosystems and the water resources depletion. Development and practical application of low-waste and non-waste technological processes with local purification of wastewater, which provide the treated water recycling and bringing the extracted valuable components to the marketable product or a secondary raw material, is one way of solving the problem of environmental protection and resource saving.

The main hydrosphere pollutants include compounds of the second class of hazard, they are phenol and formaldehyde. Phenol is a general protoplasmic poison and is toxic to all cells. The toxic effect of phenol is directly related to the concentration of free phenol in the blood. Phenol leads to gastrointestinal disorders, liver and kidneys diseases and also is a cause of oncological diseases. Formaldehyde causes injury of the central nervous system, liver, eyes, and it has allergenic, mutagenic, sensitizing, carcinogenic effect [1-3].

Phenol and formaldehyde are mostly contained in the wastewater of pulp and paper, leather, chemical industries (including the production of pesticides, organic pigment, varnishes, explosives, synthetic resins, plastics), and also production of drugs. The concentration of phenol and formaldehyde in wastewater can reach $10 \mathrm{~g} / \mathrm{dm}^{3}$. For example, in the production of phenol-formaldehyde resins of the novolac type, the waste water generated in the production process contain $2-5 \mathrm{~g} / \mathrm{dm}^{3}$ of phenol, $1.5-4 \mathrm{~g} / \mathrm{dm}^{3}$ formaldehyde. Novolac resins are widely used in the production of molding powders, press materials with fibrous and sheet metal filler (asbestos, etc.), spirit varnishes, insulating and hardening mastics, grinding disks, and also as the binders, additives to other resins, foam materials.

The practical methods of extraction of formaldehyde and phenol from the waste water have several disadvantages: significant expenses of chemicals, heat and electricity are required, use of expensive equipment, high temperatures, often accompanied by the formation of secondary pollution. The solution to the problems of waste water

\footnotetext{
Please cite this article in press as: Timoshchuk I. V. The user of adsorption for purification of wastewater from the production of phenolformaldehyde resins. Science Evolution, 2016, vol. 1, no. 1, pp. 26-33.

Copyright (C) 2016, KemSU. This is an open access article distributed under the terms of the Creative Commons Attribution 4.0 International License (http://creativecommons.org/licenses/by/4.0/), allowing third parties to copy and redistribute the material in any medium or format and to remix, transform, and build upon the material for any purpose, even commercially, provided the original work is properly cited and states its license. This article is published with open access at http://science-evolution.ru/.
} 
purification involves the development and wide introduction in practice of new reliable and efficient technological processes.

For the purification of waste water from organic compounds, the activated carbon adsorption is often effective. To create effective technologies of adsorptive waste water purification from organic compounds by carbon sorbents, it is necessary to conduct an integrative study including the balance, kinetics and dynamics of adsorption.

The aim of this work is to develop environmentally friendly adsorption technology for cleaning waste water from the mixture of phenol and formaldehyde with closed material flows, which allows to reuse purified water and to extract valuable components.

\section{MATERIALS AND METHODS}

The following objects of research were selected: AC (activated carbon) grades AG-OV-1, BAU, SKD-515, and AG-3 (JSC "Sorbent", Perm), KsAU (coconut charcoal, "Eurocarb", England), ABG (brown semicoke, CJSC "Carbonica-f", Krasnoyarsk), all objects differ in raw materials, production process, chemical surface condition, technical characteristics; aqueous solutions of formaldehyde and phenol with a variable content of organic substances $\left(0.0001-70 \mathrm{~mole} / \mathrm{dm}^{3}\right)$ and a mixture thereof.

The equilibrium adsorption of phenol and formaldehyde mixture was studied in the ratio

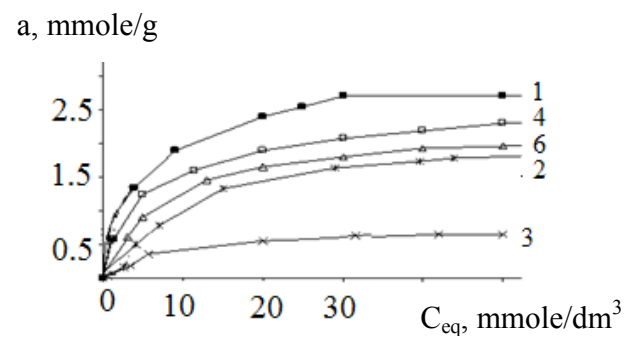

(a)
$1: 2\left(\mathrm{~mole} / \mathrm{dm}^{3}\right)$. The selected ratio of organic components corresponds to their content in the waste water of phenol-formaldehyde resins production. The research of the kinetics and dynamics adsorption of systems formaldehyde - phenol - water - AC was conducted with a help of phenol water solutions at a concentration of $25 \mathrm{~mole} / \mathrm{dm}^{3}$, and formaldehyde $50 \mathrm{~mole} / \mathrm{dm}^{3}$. The content of phenol and formaldehyde in the samples was determined by molecular absorption spectroscopy.

\section{RESULTS AND DISCUSSION}

To clarify the particularities, regularities and mechanism of the formaldehyde and phenol adsorption, there were carried out experimental studies of the adsorption extraction of formaldehyde and phenol from solutions of individual components by carbon adsorbents, then the adsorption isotherms were built (Fig. 1) and also the structure of the sorbents and chemical state of the AC surface was determined. The adsorption isotherms are in normal state and according to the Hilsa's classification based on the shape they belong to the class L, assuming the physical nature of adsorption. Analysis of adsorption isotherms of organic substances shows that the maximum adsorption capacity of AC depends on the nature of raw materials (Table 1), the structure of the carbons (Table 2) and chemical state of the surface (Table 3).

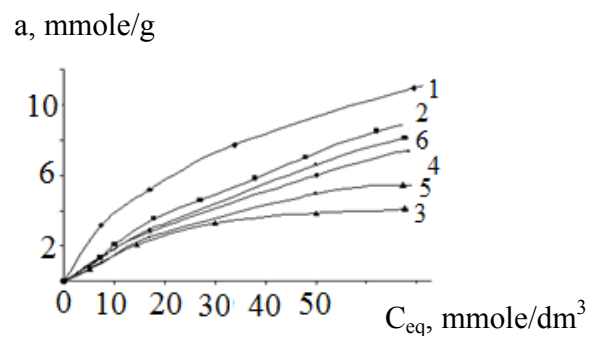

(b)

Fig. 1. Adsorption isotherms of organic substances: (a) phenol and (b) formaldehyde from the individual aqueous solutions on carbon adsorbents ( 1 - KsAU, 2 - AG-3, 3 - ABG, 4 - SKD-515, 5 - BAU, 6 - AGOV-1).

Table 1. Main characteristics of the void structure of studied activated carbons

\begin{tabular}{|l|c|c|c|c|}
\hline \multicolumn{1}{|c|}{ Sample } & $\mathrm{S}_{\text {micro }}, \mathrm{m}^{2} / \mathrm{g}$ & ${ }^{\mathrm{a}} \mathrm{V}_{\mathrm{S}}, \mathrm{cm}^{3} / \mathrm{g}$ & $\mathrm{V}_{\text {micro }}, \mathrm{cm}^{3} / \mathrm{g}$ & ${ }^{\mathrm{b}} \mathrm{V}_{\text {meso }}, \mathrm{cm}^{3} / \mathrm{g}$ \\
\hline ABG & - & 0.260 & 0.020 & 0.240 \\
\hline AG-3 & 490 & 0.34 & 0.27 & 0.06 \\
\hline AG-OV-1 & 369 & 0.459 & 0.218 & 0.241 \\
\hline BAU & 586 & 0.455 & 0.352 & 0.103 \\
\hline SKD-515 & 404 & 0.561 & 0.359 & 0.202 \\
\hline KsAU & 1418.7 & 0.73 & 0.62 & 0.11 \\
\hline
\end{tabular}

Table 2. Technical parameters of AC

\begin{tabular}{|l|c|c|c|c|c|c|}
\hline Grade of carbonic sorbent & AG-OV-1 & AG-3 & SKD-515 & BAU & ABG & KsAU \\
\hline Particle size, $\mathrm{mm}$ & $1.5-2.8$ & $1.0-1.5$ & $0.5-1.5$ & $0.1-0.4$ & $0.1-3$ & $1.5-3.0$ \\
\hline Raw material & stone coal & stone coal & stone coal & solid hardwoods & brown semi-coke & coconut shell \\
\hline Bulk density, $\mathrm{g} / \mathrm{cm}^{3}$ & 0.52 & 0.465 & 0.52 & 0.24 & 0.49 & $0.44-0.48$ \\
\hline Resistance, $\%$ & 70 & 88 & 75 & - & 53,2 & 98 \\
\hline Specific surface of pore & $700-800$ & 810 & 850 & 540 & 500 & 1512 \\
space, $\mathrm{m}^{2} / \mathrm{g}$ & & & & & \\
\hline Capacity size, $\mathrm{cm}^{3} / \mathrm{g}$ & 0.32 & 0.26 & 0.28 & 0.25 & 0.09 & 0.62 \\
micropore & 0.14 & 0.09 & 0.11 & 0.1 & 0.38 & 0.11 \\
mesopore & 0.44 & 0.53 & 0.33 & - & 0.12 & 0.22 \\
macropore & $0.76-0.84$ & 0.88 & $0.7-1.0$ & 0.38 & $0.38-0.57$ & $1.65-1.8$ \\
\hline Pore bulk volume, $\mathrm{cm}^{3} / \mathrm{g}$ & & & & & \\
\hline
\end{tabular}


Table 3. Surface condition of AC

\begin{tabular}{|l|c|c|c|c|c|}
\hline \multirow{2}{*}{$\begin{array}{c}\mathrm{N}_{\mathrm{kfg},} \\
\text { mole-eq/g }\end{array}$} & \multicolumn{5}{|c|}{ Carbonic sorbents } \\
\cline { 2 - 6 } & SKD-515 & AG-OV-1 & AG-3 & ABG & KsAU \\
\hline- OH phenolic $_{-\mathrm{COOH}_{\text {strong }} \text { carboxylic }}$ carbe & - & 0.213 & 0.321 & 0.130 & 0.194 \\
\hline$-\mathrm{COO}_{\text {lactone }}$ & 0.157 & 0.032 & 0.035 & 0.020 & 0.090 \\
\hline
\end{tabular}

Presented data (Fig. 2) show that the efficiency of adsorption also depends on the physical and chemical properties of substances. The higher formaldehyde solubility in water $\left(12400 \mathrm{mg} / \mathrm{dm}^{3}\right)$ compared to phenol $\left(925 \mathrm{mg} / \mathrm{dm}^{3}\right)$ and the ability of formaldehyde to form clusters in the solution reduces the sorption capacity due to the dispersion interactions in all carbonic sorbents. Under these conditions, formaldehyde is more favorably adsorbed on the surface of active groups, forming a secondary adsorption centers. The adsorption of formaldehyde continues on the secondary adsorption centers in the area of high concentration, forming new active centers for the formaldehyde adsorption.

To characterize carbon materials and calculate adsorption parameters there were used the Freundlich's and Langmuir's equations (theory of monomolecular adsorption), the Dubinin-Radushkevich's equation (the theory of volume filling of micropores) and the BET equation (the Brunauer-Emmet-Taylor theory of multimolecular adsorption) [4]. The applicability of the equations for calculating the parameters of adsorption was determined by preliminary experimental and theoretical studies. It is established that all the equations can be applied to describe the adsorption process of the studied organic substances.

The maximum adsorption scope for phenol and formaldehyde is in the range $0.09-1.16 \mathrm{dm}^{3} / \mathrm{kg}$ and we can suggest that the adsorption of organic contaminants from solutions of individual substances is subjected to the mechanism of micropores volume filling for the studied ACs. The values of characteristic energy, which is in the range of $10.10-15.90 \mathrm{~kJ} / \mathrm{mole}$, indicate that the adsorption runs mainly in AC's micro- and mesopores, and for activated carbon $\mathrm{ABG}$ - in mesopore. Adsorption isotherms of organic AC substances and the calculated values of the adsorption heats $(10.80-17.70 \mathrm{~kJ} / \mathrm{mol})$ allow us to make a conclusion about the physical nature of organic substances interaction with the studied AC's surface, moreover phenol has predominantly dispersive (nonspecific) and partially specific interaction due to the hydrogen bond formation. As for formaldehyde, a specific interaction with the acid functional groups of the AC's surface is more typical, the secondary adsorption centers for molecules of formaldehyde are formed.

It is established that the efficiency of organic substances extraction from AC's water in static conditions changes in the following sequence: phenol $\mathrm{KsAU}>\mathrm{SKD}-515>\mathrm{AG}-\mathrm{OV}-1>\mathrm{AG}-3>\mathrm{ABG}$, formaldehyde $-\mathrm{KsAU}>\mathrm{AG}-3>\mathrm{AG}-\mathrm{OV}-1>$ SKD-515 > BAU $>$ ABG.

Due to the fact that waste water typically contains mixtures of organic substances, we investigated the equilibrium adsorption of formaldehyde and phenol from aqueous solution of their AC's mixture.

On the basis of experimental studies of the adsorptive formaldehyde and phenol extraction from AC's aqueous mixtures, adsorption isotherms presented in Fig. 3 were plotted.

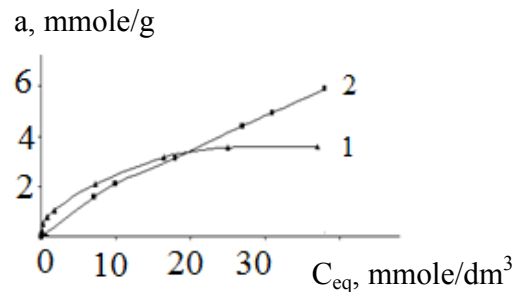

(a)

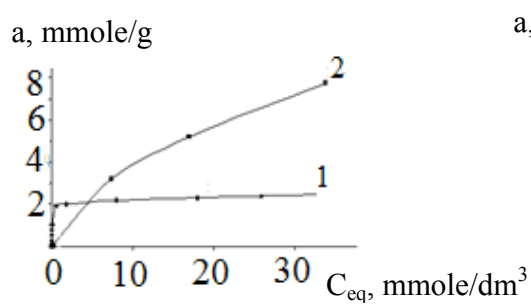

(b)

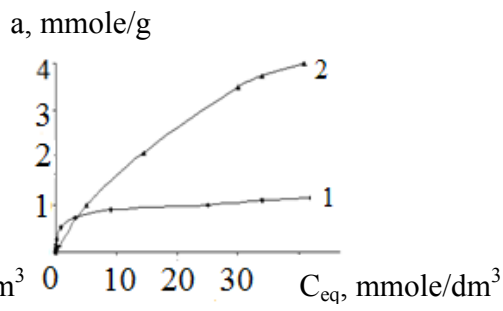

(c)

Fig. 2. Adsorption isotherms of organic substances: (1) phenol and (2) formaldehyde on the carbonic sorbents (a) KsAU, (b) AG-3, (c) ABG.

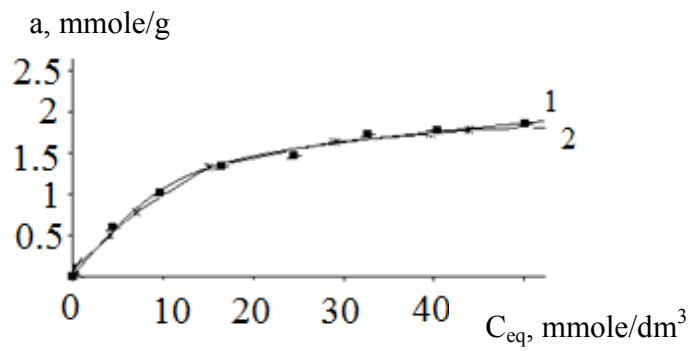

(a)

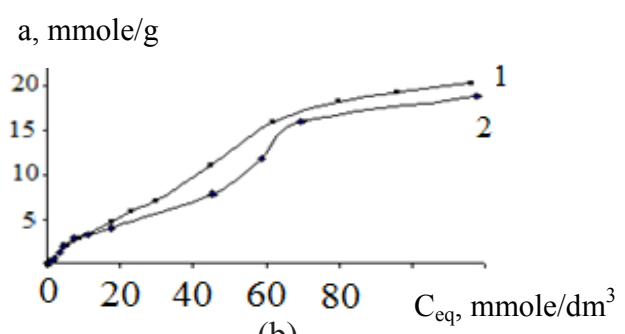

(b)

Fig. 3. Adsorption isotherms of organic substances: (a) phenol (b) formaldehyde on the carbonic sorbent AG-3 ( 1 - individual component, 2 - mixture of components) 
It is known that during the adsorption of the mixed components, the adsorption places are to be competitive, causing a decrease in adsorption of components compared with the adsorption from individual solutions. This change is due to the solubility [5]: if solubility differs greatly - the adsorption of the more soluble component is greatly reduced, less soluble - varies slightly. A comparison of adsorption isotherms of phenol and formaldehyde from aqueous solution of their mixture with isotherms adsorption from aqueous solutions of the individual components showed that such pattern as formaldehydephenol-water is observed only for formaldehyde at a concentration more than $10 \mathrm{~mole} / \mathrm{dm}^{3}$. From the mixture formaldehyde is adsorbed slightly weaker than that from its aqueous solution of the individual substance.

Thus, the flattening of isotherms is observed, which may indicate the changing nature of interaction between the components in solution and with the AC's surface. Changing of the adsorption isotherm's shape of formaldehyde from a AC's mixture on the AG-3 from $\mathrm{L}$ to $\mathrm{S} 4$, means the increase of the activation energy and strong force of interaction between the adsorbed molecules than between the dissolved substance and the $\mathrm{AC}$, as well as the desire of the solute molecules reside on the surface in the form of chains or clusters [6].

The decrease of phenol adsorption in the joint presence of organic substances is not observed due to its lower concentration than in an individual solution, lower solubility and ability to adsorb by van der Waals forces in the micropores.

Adsorption isotherms calculated with the help of Dubinin-Radushkevich's, Freundlich's and BET equations (with the exception of the Langmuir equation) correspond with the experimentally obtained adsorption isotherms on the $\mathrm{AC}$, which indicates the possibility of application of these equations to calculate the parameters of phenol and formaldehyde adsorption in static conditions from aqueous solutions of their mixtures. The calculated values of the adsorption parameters of organic substances from mixed aqueous solutions of all carbons are given in Tables 4, 5 .

The values of maximum adsorption scope for phenol and formaldehyde suggest that the organic substances adsorption in the joint presence is subjected to the mechanism of micropores volume filling for the studied ACs. The values of characteristic energy indicate that the phenol and formaldehyde sorption runs mainly in adsorbent's micro- and mesopores. The value of adsorption heat at a low filling of pores by carbon sorbents for phenol imply the adsorption caused by van der Waals forces (dispersion interaction), and also due to the formation of hydrogen bonds (specific interaction). The value of adsorption heat for formaldehyde give reason to believe, that during its adsorption a specific interaction dominates due to the formation of hydrogen bonds with the surface polar functional groups, meaning that absorption of phenol and formaldehyde active coal is the total process of nonspecific adsorption (to the extent then available) and specific (active centers).

To clarify the mechanism of adsorption IR spectroscopic studies were carried out, which have shown that during the joint formaldehyde and phenol adsorption from aqueous solutions, we can observe an increase of aliphatic (-CH) and $\mathrm{C}-\mathrm{O}$ groups, instead of dimeric structures adsorption, at the surface of activated carbon [7]. Consequently, phenol and formaldehyde interaction in aqueous solution and on the surface of activated carbon takes place, where molecules of formaldehyde can act as secondary adsorption centers for molecules of phenol. In the case of coadsorption between these compounds, obviously, the hydrogen bonds formation effect appears which is quite fragile, suggesting the possibility of efficient regeneration of activated carbon after adsorptive purification of water from the mixture of phenol and formaldehyde.

Table 4. Parameters of phenol adsorption from AC's mixture in static conditions from aqueous solutions

\begin{tabular}{|l|c|c|c|c|}
\hline \multirow{2}{*}{ Equation type } & \multirow{2}{*}{ Adsorption parameters } & \multicolumn{3}{|c|}{ Carbonic sorbents } \\
\cline { 2 - 5 } & $\beta$ & KsAU & AG-3 & ABG \\
\hline \multirow{2}{*}{ Freundlich's } & $1 / \mathrm{n}$ & 20.28 & 7.99 & 5.00 \\
\cline { 2 - 5 } & $\mathrm{a}_{\max }, \mathrm{mole} / \mathrm{g}$ & 0.637 & 0.463 & 0.328 \\
\hline \multirow{2}{*}{$\begin{array}{l}\text { Dubinin- } \\
\text { Radushkevich's }\end{array}$} & $\mathrm{E}, \mathrm{kJ} / \mathrm{mole}$ & 4.93 & 15.94 & 0.98 \\
\cline { 2 - 5 } & $\mathrm{W}, \mathrm{dm}^{3} / \mathrm{kg}$ & 14.93 & 0.179 & 0.086 \\
\hline \multirow{2}{*}{$\mathrm{BET}$} & $\mathrm{a}_{\max }, \mathrm{mole} / \mathrm{g}$ & 1.064 & 1.43 & 0.045 \\
\cline { 2 - 5 } & $\mathrm{Q}, \mathrm{kJ} / \mathrm{mole}$ & 2.00 & 13.44 & 16.96 \\
\hline
\end{tabular}

Table 5. Parameters of formaldehyde adsorption from AC's mixture in static conditions from aqueous solutions

\begin{tabular}{|l|c|c|c|c|}
\hline \multirow{2}{*}{ Equation type } & \multirow{2}{*}{ Adsorption parameters } & \multicolumn{3}{|c|}{ Carbonic sorbents } \\
\cline { 2 - 5 } & & KsAU & AG-3 & ABG \\
\hline \multirow{2}{*}{ Freundlich's } & $\beta$ & 2.58 & 2.87 & 1.37 \\
\cline { 2 - 5 } & $1 / \mathrm{n}$ & 1.0308 & 0.9456 & 0.8425 \\
\hline \multirow{2}{*}{$\begin{array}{l}\text { Dubinin- } \\
\text { Radushkevich's }\end{array}$} & $\mathrm{a}_{\max }, \mathrm{mole} / \mathrm{g}$ & 33.45 & 21.83 & 14.00 \\
\cline { 2 - 5 } & $\mathrm{E}, \mathrm{kJ} / \mathrm{mole}$ & 13.57 & 0.59 & 0.33 \\
\hline \multirow{2}{*}{ BET } & $\mathrm{W}, \mathrm{dm}^{3} / \mathrm{kg}$ & 1.231 & 23.80 & 17.54 \\
\cline { 2 - 5 } & $\mathrm{a}_{\max }, \mathrm{mole} / \mathrm{g}$ & 33.33 & 22.24 & 16.70 \\
\hline
\end{tabular}


According to the experimental data of kinetic studies, graphic charts of the adsorption relative values from phase contact time ( $t$ ) during the adsorption of organic substances by carbonic sorbents (Fig. 4) are plotted, and also such kinetic curves as experimental $\gamma$ from $\mathrm{t}$ and theoretical $\gamma$ from $\mathrm{T}$. On the basis of comparison of theoretical $\gamma-\mathrm{T}$ and experimental $\gamma-\mathrm{t}$ kinetic curves for the same values of $\gamma$, graphic $\mathrm{T}$ from $t$ charts were plotted (Fig. 5). It is known [8] that if the linear dependence of $\mathrm{T}$ from $\mathrm{t}$ describes the line passing through the central point, then the limiting stage of the adsorption is an external mass transfer, i.e. the rate of adsorbing molecules delivery from solution to the external surface of the grain is less than the speed of their migration in the adsorption space. The deviation from the linear dependence shows that over time the rate of adsorption process is more influenced by internal diffusion. Presented in Fig. 5 data confirm that the adsorption process is controlled by external mass transfer for all studied sorbents.

The values of external mass transfer coefficients, which are necessary to calculate the dynamics of adsorption, are given in table 6 . The proximity of the calculated external mass transfer coefficients to each other also indicates that the adsorption process on all $\mathrm{AC}$ in the initial moment of time is controlled by external mass transfer.

During the adsorption process of formaldehyde and phenol mixture, the external mass transfer determines the rate of the adsorption process for formaldehyde on

\section{a, mmole/g}

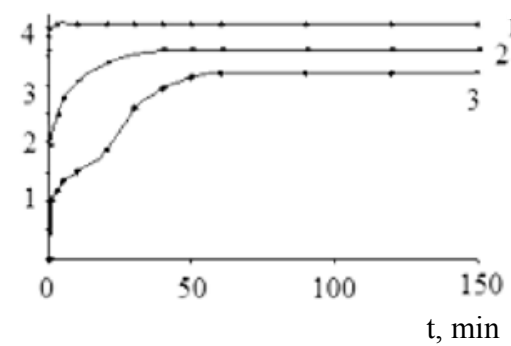

(a)
$\mathrm{KsAU}-25 \mathrm{~min}$, on $\mathrm{ABG}-40 \mathrm{~min}$, on $\mathrm{AG}-3$ - $20 \mathrm{~min}$; for phenol on $\mathrm{KsAU}-15 \mathrm{~min}$, on $\mathrm{AG}-3$ to $20 \mathrm{~min}$, on $\mathrm{ABG}-10 \mathrm{~min}$. Over the course of time, the total adsorption rate begins to influence on the porediffusion transfer process.

Presented data allow for the conclusion that the adsorption process of phenol and formaldehyde from aqueous solutions is limited by external mass transfer from 10 to 40 minutes depending on the nature of organic substances and properties of activated carbon. This fact offers an opportunity to speed up the filtration while maintaining a high efficiency of organic substances extraction from water [9].

The continuous process of adsorption dynamics of a phenol and formaldehyde mixture was experimentally investigated on AC AG-3. The adsorption was carried out in glass columns of $1.7 \mathrm{~cm}$ in diameter with the height of the sorbent layer $-0.5 \mathrm{~m}$ and a linear flow rate of $1 \mathrm{~m} / \mathrm{h}$. In order to reduce the scope of investigation and optimize industrial units there was explored the possibility of the modeling process based on the fundamental equation of adsorption dynamics using the adsorption constants of Dubinin Radushkevich and kinetic data. For the pore-diffusion dynamics equations have solutions depending on the shape of the isotherms [10-12]:

for Langmuir isotherm

$$
\tau=\frac{a_{o}}{\mathrm{v} C_{0}} \cdot\left\{L-\frac{w}{\beta_{n}} \cdot\left[\frac{1}{p} \ln \left(\frac{C_{o}}{C}-1\right)+\ln \frac{C_{o}}{C}-1\right]\right\}
$$

\section{a, mmole/g}

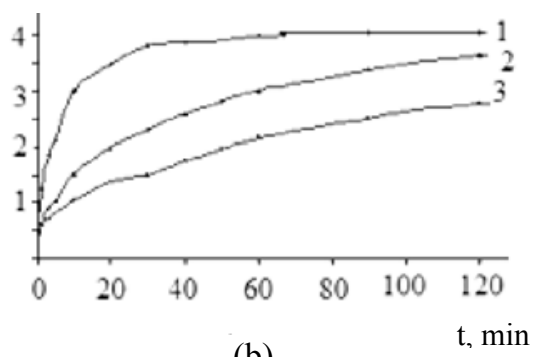

(b)

Fig. 4. Kinetic dependences of adsorption of organic substances: (a) formaldehyde and (b) phenol in their joint presence by carbonic sorbents ( $1-\mathrm{KsAU}, 2-\mathrm{AG}-3,3-\mathrm{ABG})$.

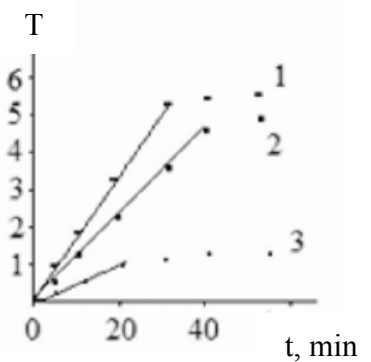

(a)

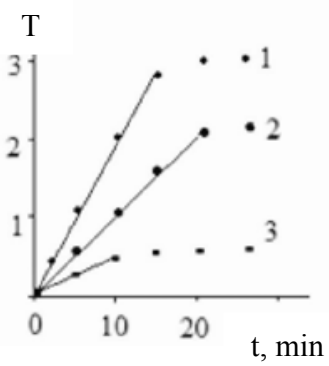

(b)

Fig. 5. Characteristic curves of T from t adsorption of (a) formaldehyde and (b) phenol: 1 - KsAU, 2-AG-3, 3 - ABG.

Table 6. Coefficients of external mass transfer in the system phenol-formaldehyde -water - AC

\begin{tabular}{|l|l|l|l|}
\hline \multicolumn{1}{|c|}{ Substence $\beta_{\Pi}, \mathrm{sec}^{-1}$} & AG-3 & KsAU & ABG \\
\hline Formaldehyde (in the presence of phenol) & 0.061 & 0.445 & 0.015 \\
\hline Phenol (in the presence of formaldehyde) & 0.059 & 0.421 & 0.014 \\
\hline
\end{tabular}


for linear isotherm

$$
\sqrt{\tau}=\sqrt{\frac{a_{0}}{w \cdot C_{0}}} \cdot \sqrt{H}-b \sqrt{\frac{a_{0}}{\beta_{n} \cdot C_{0}}},
$$

for concave isotherm in region of weak concentration

$$
\tau=\frac{a_{o}}{w C_{o}}\left[H-\frac{w}{\beta_{n}}\left(\ln \frac{C_{o}}{C}-1\right)\right],
$$

where $\tau$ - time of activated carbon layer performance of $\mathrm{N}(\mathrm{m})$ in length, until breakthrough concentration of sorbate (c) is produced; $C_{o}$ - initial concentration of the substance in the flow $\left(\right.$ mole $\left./ \mathrm{dm}^{3}\right) ; a_{\mathrm{o}}$ - substance content in the stationary phase in equilibrium with $C_{o}(\mathrm{~mole} / \mathrm{kg})$; $\beta_{n}$ - external mass transfer coefficient $\left(\mathrm{sec}^{-1}\right)$.

Fig. 6 shows the experimental and theoretical curves of dynamic formaldehyde and phenol adsorption. The coincidence of experimental and calculated according to the equation (3) curves indicates the feasibility of using this equation for modeling the adsorption process of formaldehyde and phenol, and also confirms the robustness of the proposed approach to modeling of adsorption and gives the possibility to determine the dynamic characteristics of adsorption without additional experimental studies. During the continuous purification of water containing a mixture of organic substances phenol-formaldehyde, at first the breakthrough of dominant component- formaldehyde from column is observed, that allows to simulate the process of adsorption on the dominant component.

The results of the adsorption process modeling of the studied mixtures the basic parameters of the dynamics of adsorption are determined: the working layer length, the unused layer length, the coefficient of protective action, which allowed to establish the duration of column operation and the amount of purified water depending on the throughput rate, the height of the fixed bed and the size of the column. The operation period of $1 \mathrm{~m}$ diameter column at different rates of flow of purified water for the studied sorbents are presented in table 7 , the amount of purified water until the breakthrough of formaldehyde in the filtrate (Table 8).

The operating time of the filtering layer until the breakthrough decreases in such sequence: KsAU > AG-3 > ABG. Studies of the formaldehyde adsorption in the presence of phenol in dynamic conditions showed the greatest efficiency of AC grade KsAU, but considering its high cost, the sorbent grade AG-3 can be recommended for the purification of wastewater containing mixture of phenol and formaldehyde.

In the process the efficiency of adsorption filters for removing contaminants decreases over time, therefore, to restore the adsorptive capacity of sorbents their periodic regeneration is required. We propose the technology of AC regeneration after the studied phenol-

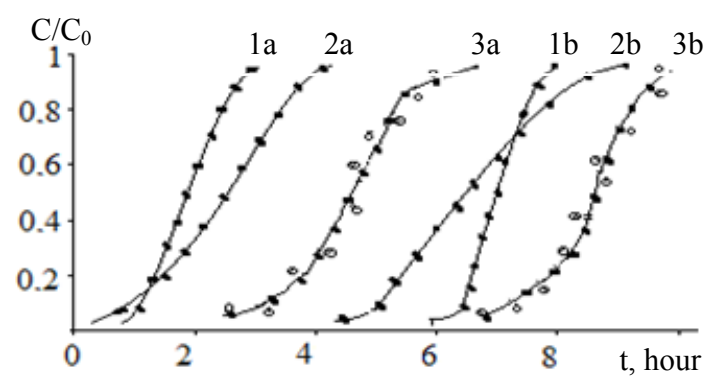

Fig. 6. Final curves of aqueous solutions adsorption of (a) formaldehyde (b) phenol for AC AG-3 at a flow rate of $1 \mathrm{~m} / \mathrm{h}$ and the height of sorbent layer is $0.5 \mathrm{~m}$ : $\bullet$ - calculated from the equations $1,2,3$; ० - experimental.

Table 7. Operating time of the column for sorbents AG-3, ABG, KsAU

\begin{tabular}{|l|c|c|c|c|c|c|}
\hline \multirow{2}{*}{$\begin{array}{c}\text { The flow rate of } \\
\text { purified water }\end{array}$} & \multicolumn{4}{|c|}{ The height of loading layer for AC } \\
\cline { 2 - 7 } & $1 \mathrm{~m}$ & $2 \mathrm{~m}$ & $1 \mathrm{~m}$ & $2 \mathrm{~m}$ & \multicolumn{2}{c|}{ ABG } \\
\cline { 2 - 7 } & $72 \mathrm{~h}$. & $288 \mathrm{~h}$. & $50.4 \mathrm{~h}$. & $216 \mathrm{~h}$. & $43.2 \mathrm{~h}$. & $180 \mathrm{~h}$. \\
\hline $10 \mathrm{~m} / \mathrm{h}$ & $108 \mathrm{~h}$. & $576 \mathrm{~h}$. & $93.6 \mathrm{~h}$. & $284 \mathrm{~h}$. & $76.6 \mathrm{~h}$. & $219 \mathrm{~h}$. \\
\hline $5 \mathrm{~m} / \mathrm{h}$ & $648 \mathrm{~h}$. & $2428 \mathrm{~h}$. & $473.2 \mathrm{~h}$. & $1746.6 \mathrm{~h}$. & $288 \mathrm{~h}$. & $1021.5 \mathrm{~h}$. \\
\hline $1 \mathrm{~m} / \mathrm{h}$ & &
\end{tabular}

\begin{tabular}{|c|c|c|c|c|c|c|c|c|c|}
\hline \multirow{3}{*}{$\begin{array}{l}\text { The height } \\
\text { of loading } \\
\text { layer for AC }\end{array}$} & \multicolumn{9}{|c|}{ The flow rate of purified water on $\mathrm{AC}$} \\
\hline & \multicolumn{3}{|c|}{ KsAU } & \multicolumn{3}{|c|}{ AG-3 } & \multicolumn{3}{|c|}{$\mathrm{ABG}$} \\
\hline & $10 \mathrm{~m} / \mathrm{h}$ & $5 \mathrm{~m} / \mathrm{h}$ & $1 \mathrm{~m} / \mathrm{h}$ & $10 \mathrm{~m} / \mathrm{h}$ & $5 \mathrm{~m} / \mathrm{h}$ & $1 \mathrm{~m} / \mathrm{h}$ & $10 \mathrm{~m} / \mathrm{h}$ & $5 \mathrm{~m} / \mathrm{h}$ & $1 \mathrm{~m} / \mathrm{h}$ \\
\hline $1 \mathrm{~m}$ & $133 \mathrm{~m}^{3}$ & $134 \mathrm{~m}^{3}$ & $374 \mathrm{~m}^{3}$ & $70 \mathrm{~m}^{3}$ & $88 \mathrm{~m}^{3}$ & $305 \mathrm{~m}^{3}$ & $51 \mathrm{~m}^{3}$ & $75 \mathrm{~m}^{3}$ & $92 \mathrm{~m}^{3}$ \\
\hline $2 \mathrm{~m}$ & $500 \mathrm{~m}^{3}$ & $590 \mathrm{~m}^{3}$ & $648 \mathrm{~m}^{3}$ & $385 \mathrm{~m}^{3}$ & $398 \mathrm{~m}^{3}$ & $474 \mathrm{~m}^{3}$ & $218 \mathrm{~m}^{3}$ & $322 \mathrm{~m}^{3}$ & $205 \mathrm{~m}^{3}$ \\
\hline
\end{tabular}

Table 8. Quantity of purified water until formaldehyde breakthrough 


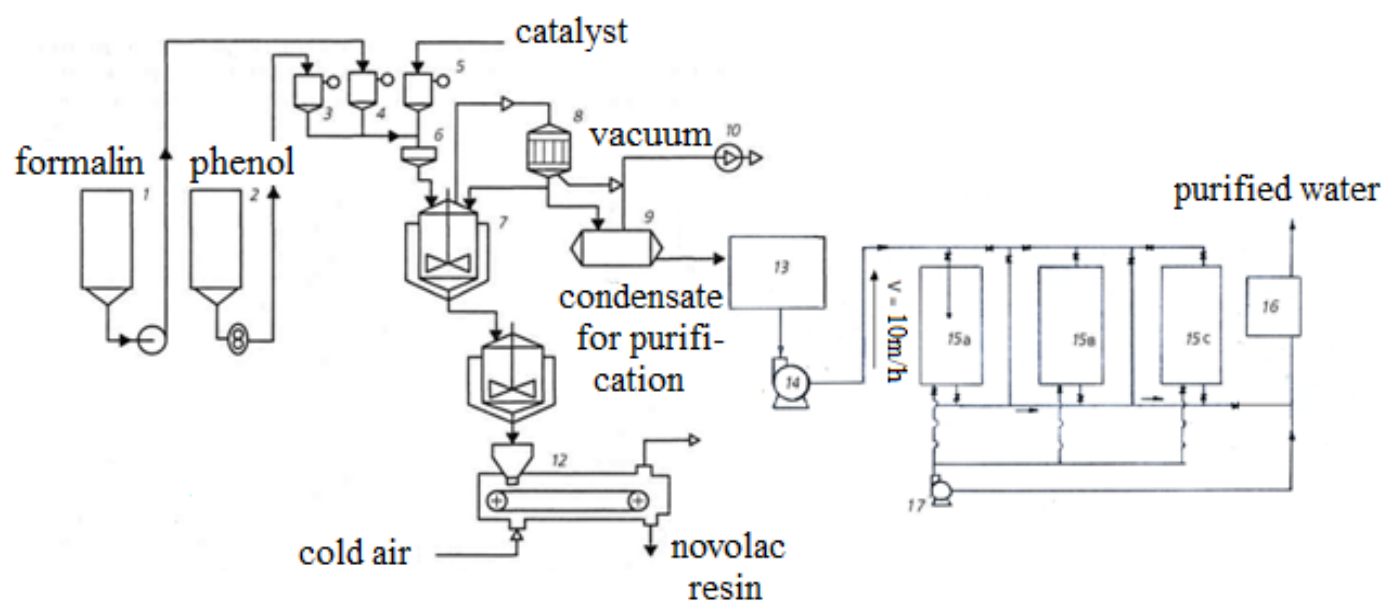

Fig. 6. Technological scheme of novolac resins production with a help of periodical method, including the stage of waste water adsorption purification

formaldehyde mixture adsorption, namely-using of carbonic sorbent washing the with water heated to $50^{\circ} \mathrm{C}$, followed by heating to $200^{\circ} \mathrm{C}$ for 2 hours, allowing to recover the sorption capacity of AC to $95-98 \%$. To select the temperature of thermal regeneration the derivatographic research was held. The estimation of the AC adsorption properties recovery after aqueous mixtures adsorption in the laboratory revealed that after the fifth cycle of regeneration-sorption adsorption capacity decreased by $15 \%$.

To increase the environmental safety and save the resources for production of phenol-formaldehyde resins, we propose to add the adsorptive purification of waste waters in the existing technological scheme of novolac resins production with a help of periodic method.

The technological process of producing the solid novolac resin with the help of periodic method consists of the following stages: preparation, loading and condensation of the raw material, drying the resin, its pouring, cooling and grinding [13]. Formalin and phenol from containers $(1,2)$ (Fig. 6) are pumped in the weight measuring tanks $(3,4)$, from which they by gravity come in condensing and drying the reactor (7) through a strainer (6). A reactor is equipped with anchor type stirrer, heating and cooling jacket and tubular cooler (5). In the period of raw material polyfunctional condensation it works in a closed cycle (such as reverse); water vapor, formaldehyde and phenol are condensed and returned to the reactor. Resin from the reactor (7) is merged into the intermediate tank (11), where the temperature is $90-130^{\circ} \mathrm{C}$ and then it is moved to the granulating mill (12) and after granulation is cooled by air and arrives to the warehouse. During the resin drying all volatile substances after cooling are condensed and gathered in the collector (9). In the production of $1 \mathrm{t}$ of the novolac resin 1.5-2.0 $\mathrm{m}^{3}$ of contaminated wastewater is formed. Wastewater containing predominantly phenol and formaldehyde accumulated in the tank (13) are moved to the adsorption unit for purification. The adsorption unit with a fixed bed of sorbent includes three adsorption filter (15) of $2 \mathrm{~m}$ in diameter and a loading layer height of $3 \mathrm{~m}$, filled with activated carbon grade AG-3, the pump (14) for supplying wastewater with a filtration rate of $10 \mathrm{~m} / \mathrm{h}$ and drainage of purified water (16). The activated carbon is to be unloaded after the drain of remaining in the column liquid. For a complete emptying of the column, the remaining water is pumped (17). Purified water and emitted at the regeneration stage phenol and formaldehyde are returned to the production cycle.

\section{CONCLUSIONS AND RECOMMENDATIONS}

Based on the results of systematic approach to the study of adsorption from aqueous medium by sorbents of different nature, mass transfer, optimization of filter parameters and modes of sorption purification, there was developed a technology of wastewater adsorptive purification from organic components, which allows to increase ecological safety and to save the resources for production of phenol-formaldehyde resins due to the reuse of purified water and recycling the extracted organic substances.

The developed technology can be used in other industries, in which wastewater also contains phenol and formaldehyde mixture, for example, the production of organic pigment, varnishes, explosives. The proposed technology can be implemented on the basis of equipment produced in our country.

\section{REFERENCES}

1. Grushko Ya.M. Vrednye organicheskie soedinenija $v$ promyshlennyh stochnyh vodah [Harmful organic compounds in industrial wastewater]. Leningrad: Khimiya Publ., 1982. 216 p.

2. Guseva T.V., Molchanova Ya.P., Zaika E.A. Gidrohimicheskie pokazateli sostojanija okruzhajushhej sredy [Hydrochemical of environmental indicators]. Moscow: Forum: INFRA-M Publ., 2007. 192 p.

3. Itoh S., Gordon B., Callan P. Regulations and perspectives on disinfection by-products: importance of estimating overall toxicity. Journal of Water Supply: Research and Technology-Aqua, 2011, vol. 60, no. 5, pp. 261-274. 
4. Timoshchuk I.V. K voprosu podgotovki vody dlja pishhevoj promyshlennosti [On the issue of water treatment for food industry]. Tehnika i tehnologija pishhevyh proizvodstv [Engineering and technology of food production], 2010, no. 3, pp. 111-116.

5. Timoshchuk I.V. Formirovanie kachestva produktov pitanija na osnove razrabotki i primenenija adsorbcionnyh processov $v$ tehnologijah ochistki prirodnyh vod. Diss. dokt. tehn. nauk [Formation of quality through the development and application of food adsorption processes in technologies of water purification. Dr. eng. sci. diss.]. Kemerovo, 2014. 326 p.

6. Koganovskii A.M., Klimenko N.A., Levchenko T.M., Roda I.G. Adsorbcija organicheskih veshhestv iz vody [The adsorption of organic substances from water]. Leningrad: Khimiya Publ., 1990. 256 p.

7. Timoshchuk I.V., Golubeva N.S., Krasnova T.A., Tumanova T.A. Izuchenie sostojanija poverhnosti aktivnogo uglja posle adsorbcii organicheskih soedinenij [The study of the surface state of active carbon after adsorption of organic compounds]. Jekologija i promyshlennost' Rossii [Ecology and Industry of Russia], 2010, no. 10, pp. 58-59.

8. Fedotkin I.M., Koganovskii A.M., Roda I.G., Marutovskii R.M. Ob opredelenii koeffitsienta vneshnego massoobmena pri adsorbtsii iz rastvorov [Determination of the coefficient of mass transfer during adsorption from solutions]. Zhurn. fiz. khimii [Journal. nat. chemistry], 1974, vol. 48, no. 2, pp. 473-475.

9. Krasnova T.A., Kirsanov M.P., Samoilova N.A., Chekannikova I.V. Kinetics of formaldehyde adsorption by activated carbon. Ecological Congress International journal, USA - Kansas - Spring, 2001, vol. 4, no. 3, pp. 5-8.

10. Koganovskii A.M., Klimenko N.A., Levchenko T.M., Marutovskii R.M., Roda I.G. Ochistka i ispol'zovanie stochnykh vod v promyshlennom vodosnabzhenii [Treatment and use of wastewater in industrial water supply]. Moscow: Khimiya Publ., 1983. $288 \mathrm{p}$.

11. Krasnova T.A., Gorelkina A.K., Timoshchuk I.V., Ozherel'eva A.V. Adsorbtsionnaya ochistka stochnykh vod ot khlorfenola i fenola [The adsorption treatment of wastewater from chlorophenol and phenol]. Voda: khimiya i ekologiya [Water: chemistry and ecology], 2011, no. 11, pp. 28-32.

12. Timoshchuk I.V., Shishkin V.V., Krasnova T.A., Kirsanov M.P. Razrabotka tekhnologii doochistki pit'evoy vody ot organicheskikh veshchestv [Development of technology for drinking water purification from organic substances]. Vestnik RUDN. Seriya Inzhenernye issledovaniya [Bulletin of Peoples' Friendship University. A series of engineering studies], 2010, no. 2, pp. 48-51.

13. Nikolaev A.F., Kryzhanovskii V.K., Shul'gina E.S., Dvorko I.M. Tekhnologiya polimernykh materialov [The technology of polymer materials]. Saint Petersburg: Professiya Publ., 2008. 533 p.

\section{Irina V. Timoshchuk}

Dr.Sci.(Eng.), Associate Professor, Professor of the Department of Analytical Chemistry and Ecology, Kemerovo Institute of Food Science and Technology (University), Kemerovo, Russian Federation. 